\title{
ISOLATION AND CHARACTERIZATION OF FLAVONE GLYCOSIDE VITEXIN FROM PEPEROMIA PELLUCIDA LINN
}

\author{
*PAPPACHEN LEENA.K. ${ }^{1,2}$, Dr. CHACKO ANNAM ${ }^{3}$ \\ ${ }^{1}$ Research Scholar, Karpagam University, Eachanari Post, Coimbatore \\ ${ }^{2}$ Amrita School of Pharmacy, Amrita Viswa Vidyapeetham University, AIMS Health Sciences Campus, Kochi \\ ${ }^{3}$ St. Josephs College of Pharmacy, Cherthala, Alappuzha \\ *Corresponding author's E-mail: leenabijudaniel@gmail.com
}

\begin{abstract}
Peperomia Pellucida Linn, widely used in traditional medicine belongs to the family Piperaceae. It has been used for treating abdominal pain, acne ,boils, colic, fatigue, gout, headache, renal disorders, and rheumatic joint pain. The whole plant after collection, authentication and drying, was extracted with petroleum ether, chloroform, methanol and water using soxhlet extractor. The aim of the study was to isolate the phytoconstituents from the methanolic extract of peperomia pellucida by Preparative-Thin Layer Chromatography (P-TLC) and characterized by spectroscopic techniques (UV-visible spectroscopy, infrared spectroscopy, $1 \mathrm{H}$ and 13C NMR spectroscopy and mass spectrometry). A flavonoidal structure was isolated from the methanolic extract of the plant. The light yellow coloured compound which solubilizes in methanol, ethanol and water having m.p. 203-204 ${ }^{\circ} \mathrm{c}$ and $\mathrm{Rf}$ value 0.61 in mobile phase acetonitrile : water: acetic acid (6:4:0.1) was identified by the various spectroscopical methods. So from this study, it is concluded that the isolated compound may be vitexin which is responsible for various pharmacological activities of the plants.
\end{abstract}

Keywords: Peperomia pellucida, Vitexin, Thin Layer Chromatography,Phytoconstituent.

\section{INTRODUCTION}

Traditional herbal remedies have always been valued since time immemorial. The plant derived substances have the advantage of creating therapeutic, prophylatic and diagnostic substances with specific functions and minimum side effects. Peperomia pellucida is an annual, shallow - rooted herb usually growing to a height of about 15 to $45 \mathrm{~cm}$. It is characterized by succulent stems, shiny, heart shaped fleshy leaves and tiny, dot like seeds attached to several fruiting spikes ${ }^{1}$. It has a mustard - like odour when crushed. Peperomia pellucida has been used as a food item as well as medicinal herb. P. pellucida has been used for treating abdominal pain, abscesses, acne, boils, colic, fatigue, gout, headache, renal disorders, and rheumatic pain, and to treat breast cancer, impotence, measles, mental disorders, and smallpox. It has been used in salads or as a cooked vegetable to help relieve rheumatic joint pain. ${ }^{2,3}$

The plant is also used as topical medicine for skin related problems such as acne, pimples and abnormal complexion. Pounded whole plant is used as warm poultice for boils, pustules and pimples (De Fatima et al., 2004). In the other parts of Asia such as Bangladesh, the aerial parts including leaves of the plant have been used by local traditional healers to treat the excited mental disorders (Khan et al., 2008). Manila Medical Society reported that P. pellucida is useful to relieve rheumatoid arthritic joint pains, but it may manifest some CNS depression side effects (Khan et al., 2008). Several scientific studies reported the antibacterial and analgesic activities of $P$. pellucida (Aziba et al., 2001; Khan and Omoloso, 2002) $)^{2,3}$ and some other studies reported the isolation of bioactive phytoconstituents with strong anti-fungal and anti-cancer properties from P. pellucida (Ragasa et al., 1998; Xu et al., $2006)^{4,5}$.

The plant Peperomia pellucida was found to have variety of chemical constituents. Phytochemical screening revealed the presence of alkaloids, cardenolides, flavanoids, terpenoids, saponins, tannins etc. The present research was therefore, undertaken to the isolation and characterization of flavone glycoside, vitexin from the methanolic extract of Peperomia pellucida linn.

\section{MATERIAL AND METHOD:}

\section{Collection \& Authentication:}

Peperomia pellucida was collected from Kollam district of Kerala( India) and was authenticated by Dr.V.J.Dominic, Sacred Heart College,Thevara. The whole plant was washed thoroughly with sufficient water. It was dried in shade for 3 weeks and powdered using mechanical grinder and sieved to get the powder of uniform size.

\section{Chemicals and instruments:}

All the chemicals and re-agents used for the experiments were of analytical grade.

\section{Isolation of Phytoconstituent:}

Hundred grams of dry powder of the whole plant of peperomia pellucida were successively extracted with petroleum ether and chloroform for the removal of fatty material, steroids etc. The remaining powder was exhaustively extracted in a Soxhlet apparatus with methanol. After the evaporation of methanol under vacuum, the extract was dried. The dried residues were 
dissolved in methanol and subjected to Thin Layer Chromatography. Silica gel was used as the stationary phase and acetonitrile : water: acetic acid (6:4:0.1) as the mobile phase in the TLC.

On the chromatograms the light yellow bands of vitexin with $\mathrm{Rf}$ value of 0.61 were located. These bands were carefully eluted and extracted with methanol. The solvent evaporated from the resulting extracts and residue thus obtained was subjected to various physical and spectral analysis $^{6}$.

Chemical identification of Constituents: A little amount of the isolated constituent was dissolved in alcohol and subjected to the following tests ${ }^{7}$.

Shinoda Test (Magnesium Hydrochloride reduction test): To the test solution, add few fragments of Magnesium ribbon and concentrated Hydrochloric acid drop wise .Observe the colour.

Ammonia test: Filter paper dipped in alcoholic solution of the drug was exposed to ammonia vapour. Formation of yellow spot on the filter paper observed.

Zinc Hydrochloride Reduction Test: To the test solution add a mixture of Zinc dust and conc. Hydrochloric acid. Heat the solution and observe the color.

Vanillin HCl test: Vanillin $\mathrm{HCl}$ was added to the alcoholic solution of the drug. Formation of pink colour due to the presence of flavonoid glycosides observed.

\section{RESULTS AND DISCUSSION:}

\section{Characterization of the compound:}

The light yellow coloured compound, melting point 203$204^{\circ} \mathrm{c}$, have been isolated. The compound is soluble in methanol, ethanol and water and shows the spectra at particular wavelength.

\section{UV Spectra:}

The UV spectra of the peaks were typical of flavonoid (UV maxima at 260-270nm and 330-370 nm). Peak showed UV absorption with maximum at $269 \mathrm{~nm}$ and $338 \mathrm{~nm}$.

\section{IR Values:}

FT-IR data showed that the isolated compound presented the characteristic intensities of $\mathrm{C}=\mathrm{O}$ absorption band at 1624 (carbonyl), 3610, 3558(hydroxyl) 2935, 1149, 1097(C-H stretch)and 1568, $1501 \mathrm{~cm}^{-1}$ (aromatic).

\section{NMR values:}

The ${ }^{1}$ H NMR [400 MHz, d 6 -DMSO] spectrum showed a chelated hydroxyl proton (d 13.18, $1 \mathrm{H}, \mathrm{s})$, an aromatic singlet (d 6.28, 1H, s), a downfield signal (d 6.79, 1H, s), suggestive of a flavonoid ${ }^{8}$ and an AA'BB' spin system [d 8.03, $(2 \mathrm{H}, \mathrm{d}, \mathrm{J}=8.5 \mathrm{~Hz})$ and $6.09(2 \mathrm{H}, \mathrm{d}, \mathrm{J}=8.5 \mathrm{~Hz})]$, attributable to a para disubstituted phenyl unit. In addition, the ${ }^{1} \mathrm{H}$ NMR spectrum showed a series of signals between d 3.19 and $3.98(6 \mathrm{H})$, characteristic of a sugar unit. The absence of usual O-glycosidic anomeric proton signal and the presence of signal at $\mathrm{d} 4.69(1 \mathrm{H}, \mathrm{d}, \mathrm{J}=9.88 \mathrm{~Hz})$ indicated the presence of a C-glycoside.

Mass Spectrum: Mass spectra of isolated constituent show Molecular ion $\mathrm{m} / \mathrm{z}$ 433. The above physical and spectral data of compound represent that the isolated constituent may be vitexin ${ }^{9}$.

\section{CONCLUSION:}

In the above study, vitexin was isolated and characterized from methanolic extract of peperomia pellucida Linn and this is a flavonoidal constituent. Vitexins are lignan compounds, induce apoptosis and suppress tumor growth, has potent anti oxidant effect and it can be effectively used for the prevention of UV-induced adverse skin reactions such as free radical production and skin cell damage $^{10}$.

Vitexin has potent hypotensive effects, by its ganglionic blocking properties .Anti-inflammatory effects of vitexin were indicated by its anti- histaminic, anti -bradykinin and anti -serotonin properties.

Additional clinical uses include anti-viral, anti -thyroidal, anti-artheriosclerotic and anti-hepatotoxic effects. The ability of vitexin to inhibit super oxide radicals, leads the potential application of its anti-ageing effects in cosmetic field.

Conflict of interest: We declare that we have no conflict of interest.

\section{REFERENCES:}

1. Ghani A: Medicinal plants of Bangladesh. Asiatic Society of Bangladesh, Dhaka, Bangladesh: 1998, 77-78.

2. Aziba PI, Adedeji A, Ekor $M$ et al: Analgesic activity of Peperomia pellucida aerial parts in mice. Fitoterapia 72: 2001, 57-58.

3. Khan MR, Omoloso AD: Antibacterial activity of Hygrophila stricta and Peperomia pellucida. Fitoterapia 73: 2002,251-254.

4. Ragasa CY, Dumato M, Rideout JA: Antifungal compounds from Peperomia pellucida. ACGC Chem Res Commun 7: 1998, 54-61.

5. Xu S, Li N, Ning MM et al: Bioactive compounds from Peperomia pellucida. J Nat Prod 69: 2006,247-250.

6. Trease GE, Evans WC: Pharmacognosy. 11th edn. Brailliar Tiridel Can. Macmillian publishers ,1989.

7. Kokate C K, Practical Pharmacognosy; Pune : Vallabh Prakashan; 2003.

8. MabryTJ, Markham K.R. and Thomas, M.B., In;The Systematic identification of flavonoids, Springer-verlag, Berlin, 1970, 267

9. Tomczyk M., Gudej J., Marek Sochacki., Z. Naturforsch, 2002, $57 \mathrm{c}, 440$.

10. Yingjun Zhou, Y. Eric Shi et al. Vitexins, Nature-Derived Lignan Compounds, Induce Apoptosis and Suppress Tumor Growth, Clin Cancer Res 15(16):5161-5169. 